\title{
O gosto do popular: dinâmicas globais e as cozinhas tradicionais
}

\section{The taste of the popular: global dynamics and the tradicional cuisines}

\author{
Kadma Marques Rodrigues - Doutora em Sociologia. Universidade Estadual do Ceará (UECE). Brasil - \\ kadma.rodrigues@uece.br
}

\section{Filipe Pessoa Camelo - Mestre em Sociologia. Universidade Estadual do Ceará (UECE). Brasil - filipepessoacamelo@uece.br}

\section{Palavras-chave:}

Gastronomia. Gosto.

Regional. Popular.

Cultura Alimentar.
Keywords:

Gastronomic Cultural Heritage. Traditional Sweets' Know-how. Traditional

Gastronomy.

\section{RESUMO}

Embora seja recorrente a associação entre processos globais de gourmetização e a reação da chamada culinária regional à dinâmica sistêmica de homogeneização alimentar, este artigo levanta a hipótese de que tais processos não rompem de fato com a submissão do local, concebido como variedade do modelo alimentar hegemônico. O objetivo deste artigo é então o de refletir acerca de uma perspectiva alternativa àquela integradora, mediante ampliação do campo gastronômico a partir de um viés não só regional, mas popular, o qual reconhece socialmente sujeitos, lugares, ambientes, utensílios e pratos ou modos de fazer, a partir do registro da diferença. Para tanto, considera-se especificamente a atuação de três restaurantes que se afirmam como representativos desta categoria de produção alimentar na capital cearense: o Albertu's, o Camocim e o Fabiano. Este último é analisado em um circuito que integra diferentes bairros e pratos, a partir da mediação de agentes privados e públicos, a exemplo do Observatório Cearense da Cultura Alimentar (OCCA).

\section{ABSTRACT}

The production of gastronomic inventories is important to register the traditional knowledge and practices of a certain region and, in this way, preserve the gastronomic cultural patrimony of this area. This study aims at identifying and performing an academic record from inventories of the gastronomic and historical sweets productions of the city of São José in the early twentieth century through to the middle of the same century. In order to reach the objective the methodology developed by Müller (2012), called the Gastronomic Cultural Reference Inventory, was compiled by a preliminary bibliographical and documentary survey, field research, practical workshops, and individualized interviews. This way, it was possible to identify the traditional sweets production, to understand and systematize the traditional techniques used by elders, as well as to verify transformations that are occurring during the production, the result of urbanization, and the strong presence of industrialization, often characterizing the original production.

Como citar este artigo

RODRIGUES, Kadma Marques; CAMELO, Filipe Pessoa. O gosto do popular: dinâmicas globais e as cozinhas tradicionais. Revista Brasileira de Gastronomia, Florianópolis, v. 1, n. 1, p. 03-17, jul./dez. 2018. Disponível em: http://rbg.sc.senac.br/index.php/gastronomia/article/view/29. Acesso em: $d d$ mm aa. 


\section{INTRODUÇÃO ${ }^{1}$}

Por onde iniciar uma reflexão sobre o "gosto do popular"? Talvez o melhor caminho seja tomar como ponto de partida a problematização dos próprios termos que integram o título deste artigo. De fato, a proposta de título parece encerrar imediatamente uma perspectiva diferenciada daquelas que guiam certas análises formuladas de modo recorrente.

Neste texto, o gosto não assume um caráter supostamente natural ou fisiológico, concebido como simples exercício sensível de capacidades gustativas. Prevalece nesta análise perspectiva semelhante àquela enunciada pelo historiador inglês Michael Baxandall (1991) quando trata da suposta naturalidade da recepção de obras plásticas - o olhar, assim como o paladar neste caso, certamente é parte fisiológico, mas também é parte cultural.

Mas não se trata de uma cultura indiferenciada, aquela que preside o resultado da experiência com os sabores. Antes, partilhando os mesmos procedimentos que circunscrevem o domínio das produções culturais sofisticadas, à exemplo novamente da recepção artística, o gosto tem sido abordado de forma recorrente pelo senso comum e pelo senso comum elaborado a partir do apagamento da história de constituição do valor atribuído a hábitos alimentares legitimados.

Sendo assim, para além da esfera sinestésica e do natural (inato), o "gosto" também pode ser entendido como "princípio de classificação" (BOURDIEU, 1983)². Quer dizer, determinada comida é ou não "do gosto" de uma pessoa ou de um grupo social, a partir das adjetivações que lhe são atribuídas: boa/ruim, bonita/feia/, quente/fria, pesada/leva, salgada/insossa etc. Estas diferenciações possuem cargas simbólicas, diretamente relacionadas às trajetórias e as posições socioculturais de cada pessoa e grupo social.

Desse modo, tais abordagens colocam entre parênteses modelos de experiências gustativas, o da "alta cultura" e da "baixa cultura", os quais concorrem de modo não declarado pela composição de insumos, de temperos, de modos de preparação e de serviço e que, no caso do popular, são diferenciadas daquelas do amador, do conhecedor, do apreciador das "boas comidas" e, portanto, do "bom gosto".

Sobre o gosto do popular, concebido em negativo, como falta ou ausência de gosto, afirmase que o prazer que este conjunto de "outros consumidores" sente diante de determinados alimentos ou pratos não se reveste verdadeiramente do prazer legítimo, conferido pela dimensão estética, sendo por isso seus ingredientes combinados de forma extrínseca à pureza da experiência gustativa sofisticada.

Os elementos da chamada cultura de massa, quando considerados no âmbito da cultura alimentar, vêm tornar este cenário ainda mais complexo. Das cadeias internacionais de comidas pré-fabricadas de preparo rápido, as quais se alastraram mundialmente seguindo a proposta de homogeneização dos gostos é possível destacar dois polos: aquele da dita mcdonaldização, mediada pelo cardápio centrado na combinação gordura-sal-açúcar das fast-food ou junkie-foods; bem como, aquele da diversificação da comida de rua representada pelos recentes food-trucks (e seu desdobramento em food-parks). Embora diferenciados, tais polos constituem tendências cujos lastros históricos remetem à um modelo de desenvolvimento calcado na moderna industrialização da agricultura; no aumento da produção de alimento e na consequente difusão da imagem de uma

\footnotetext{
${ }^{1}$ Em sua versão preliminar, este texto foi apresentado no seminário Metamorfoses do Popular, realizado pelo Programa de PósGraduação em Sociologia, na Universidade Federal do Ceará (UFC), nos dias 12 e 13 de abril de 2018.

2 Para uma discussão mais aprofundada desse autor concernente ao termo "gosto" ver A Distinção (BOURDIEU, 2007).
} 
sociedade da abundância; nos avanços técnicos em termos de conservação e de armazenamento de produtos alimentícios; na cultura urbana, marcada pela aceleração dos ritmos de vida, no lazer e na emergência do hábito de comer fora de casa; e na recente midiatização da profissão de chef de cozinha.

O olhar sobre o conceito de cultura utilizado neste artigo está vinculado à perspectiva de que esses agentes sociais (possuidores do "gosto popular") fazem parte de uma rede de significados, criada pela própria sociedade e pelo grupo social ao qual pertencem, para guiá-los no seu modo de ser e de ver o mundo (GEERTZ, 1989, LARAIA, 1997). É uma herança social acumulada e reproduzida, cotidianamente, de forma dinâmica (MORIN, 2007; SANTOS, 1994).

À luz desse prisma teórico, cultura alimentar pode ser abordada como um sistema simbólico em que indivíduos que compõem determinado espaço social conferem sentidos, classificações, valores e normas às preparações e às comercializações das comidas e bebidas (BRAGA, 2004). Desta maneira, estes elementos influenciam na determinação do que é ou não comestível e onde, com quem, como, quando, por que, por quem e quanto se deve comer. Por conseguinte, seleciona-se aquilo que está de acordo com as regras sociais e culturais interiorizadas/aprendidas.

Diante dessa miríade de perspectivas e de condicionantes, como discernir o popular do massivo no campo alimentar? Como caracterizar aquilo que circunscreveria "o próprio" do gosto presente na cultura alimentar desse segmento social?

\section{1 "Ração humana", os pobres e o popular}

Para além do campo da alta gastronomia, pode ser elucidativa da disposição incorporada para a distinção alimentar dos segmentos populares, o episódio que, em outubro de 2017, causou escândalo, ficando conhecido na imprensa de grande circulação como o caso da "ração humana". Esta história ocupou inúmeras matérias de diferentes formas da mídia brasileira durante certo tempo. A Prefeitura de São Paulo, na pessoa do Prefeito João Dória, lançou o programa "Alimento Para Todos" ${ }^{3}$, cujo cerne era um produto batizado pelo governo simplesmente como "Allimento" ou "Farinata".

Tal produto seria distribuído gratuitamente à população carente da cidade, por ONGs e instituições filantrópicas, mas também o governo municipal expressava publicamente o propósito de inseri-lo na merenda das escolas públicas. Embora sua composição fosse variável, de acordo com a matéria-prima utilizada em sua formulação, a população brasileira foi fartamente informada que a Farinata tinha por base o uso de alimentos próximos ao vencimento ou fora do padrão de comercialização em supermercados.

Esses alimentos seriam enviados à prefeitura por meio da Plataforma Sinergia ${ }^{4}$, e por esta ação os doadores receberiam benefícios econômicos e isenção de impostos. Estocados, os alimentos doados seriam submetidos a um processo de desidratação (a liofilização) o que Ihes

\footnotetext{
${ }^{3}$ No dia 8 de outubro, a Prefeitura de São Paulo sancionou o projeto de lei 16.704/2017que instituiu a Política Municipal de Erradicação da Fome e de Promoção da Função Social dos Alimentos. O programa “Alimento para Todos" vincula-se à publicação desta lei.

${ }^{4}$ A Plataforma Sinergia não apresenta histórico em seu site (http://plataformasinergia.org/index.html). É a organização que detém a tecnologia para a produção da Farinata, definindo-se como "uma rede de inteligência e soluções para a sustentabilidade que reúne consultorias, empresas, projetos sociais, ONGs, escolas e universidade". Foi fundada por Rosana Perrotti.
} 
conferiria o aspecto de pó ou de granulado cinza apresentado, com o consentimento da Igreja católica paulistana, em potes com a imagem de Nossa Senhora Aparecida.

Essa "comida genérica" guardaria, segundo o Prefeito, as propriedades de um "alimento completo", com proteínas, vitaminas e sais minerais. Apesar disso, o Conselho Regional de Nutricionistas (CRN-3) e o Conselho Municipal de Segurança Alimentar e Nutricional de São Paulo (COMUSAN), órgãos que não foram consultados sobre a criação do programa, manifestaram-se contra a proposta por entender que o citado projeto feria os princípios do Direito Humano à Alimentação Adequada (DHAA).Ele também negaria as políticas públicas de combate à fome e à desnutrição e o próprio Guia Alimentar para a População Brasileira, o qual preconiza o acesso à "alimentos de verdade".

Dentre as contradições que conferiram fragilidade ao citado projeto acha-se o fato de que a Prefeitura, lançou seu programa de combate à fome depois de ter reduzido itens da merenda escolar, mediante justificativa de combate à obesidade. Ou seja, com um discurso pautado pela aliança nutrição e saúde, o poder público paulistano retirou justo os chamados "alimentos de verdade" para incluir o dito "Allimento" sintético.

De fato, se a questão alimentar abrange certamente importantes aspectos nutricionais, ela não se reduz a estes, envolvendo igualmente aspectos sociais e culturais, nos quais se justapõem dimensões diversas (étnicas, regionais, sensoriais, antropológicas e religiosas). Remetendo, assim, à dicotomia alimento (natureza) e comida (cultura). Para DaMatta (2001), aquele é algo universal e que se aplica a todos os seres humanos, independentemente do lugar que ocupe neste mundo. É genérico, pois todos têm que ingerir os nutrientes oriundos dos alimentos - proteínas, vitaminas, lipídios, sais minerais, entre outros - para se manter vivo. E são diversas as possibilidades do ser humano conseguir prover o organismo com esses elementos, pois, como é um ser onívoro, tem a capacidade de comer de tudo, tanto de origem animal como de origem vegetal.

Entretanto, essa imposição fisiológica não implica "comer de tudo". O comensal constitui um repertório (simbólico) do que, onde, com quem, quando, quanto, como se deve comer. Assim, nem tudo que é nutritivo é comestível. Logo, o autor denomina o alimento culturalmente modificado/fabricado de "comida". Além disso, pode-se dizer que somos os únicos seres vivos que produzem alimentos que não estão postos na natureza (MONTANARI, 2008).

Encarada como elemento cultural, que abriga assim histórias, lembranças, sensações e vínculos sociais, a comida corporifica o modo de vida dos indivíduos em sociedade. Por isso, as entidades acima citadas afirmam que a restituição da dignidade aos segmentos de população que vivem sob o signo da vulnerabilidade social, passa também pelo acesso à comida, considerando aquela que é preparada, transformando os insumos produzidos no campo e na cidade 5 .

Embora o Prefeito paulista tenha vindo à público em diversos momentos tentando assegurar a realização da proposta por meio de afirmações inusitadas, a exemplo daquela em que comparava o avanço simbolizado pelo granulado àquele da invenção da "comida de astronauta"; ou de outra, em que dizia que seu sabor era semelhante ao de biscoito de polvilho; os órgão públicos e a imprensa de grande circulação não cessaram de considerar o programa como um desrespeito às

\footnotetext{
${ }^{5}$ Este foi um dos principais compromissos assumidos pela 5a Conferência Nacional de Segurança Alimentar e Nutricional, evento realizado pelo Conselho Nacional de Segurança Alimentar e Nutricional da Presidência da República, em BrasíliaDF, de 3 a 6 de novembro de 2015, com o tema: "Comida de verdade no campo e na cidade: por direitos e soberania alimentar".
} 
conquistas obtidas nas últimas décadas no campo da Segurança Alimentar e Nutricional. Mas nenhuma outra afirmação parece ter tido mais força para sepultar o citado programa do que aquela em que o Prefeito afirma, seguindo a argumentação do cardeal e arcebispo metropolitano de São Paulo, Dom Odílio Scherer, e reeditando sua própria fala, proferida em um programa televisivo veiculado no passado, de que "Pobre tem fome, e não hábito alimentar".

A dissociação entre "fome", de um lado, e "hábito alimentar", de outro, leva a fala do Prefeito à consideração de que há uma faixa da população paulistana que não só se encontra em situação de urgência orgânica (a fome), necessitando uma resposta alimentar imediata que evite a falência física, mas também que esse segmento de paulistas "pobres", que também podem ser incluídos no universo "popular", recuaram em sua humanidade o suficiente para não mais cultivarem qualquer simbolismo ou dimensão cultural associada ao ato de comer (os hábitos alimentares).

Para além do fato de que, o Ministério da Saúde afirma que não há prevalência de desnutrição em São Paulo, a população de baixa renda paulistana é concebida, neste caso, como aquela que se encontra abaixo da escala de variação "legítima" do humano, cuja condição de existência encontra-se reduzida à esfera biológica. A partir deste ponto, é possível distinguir do lado oposto da citada escala, uma outra faixa da população, aquela que é capaz de associar o hábito de ingerir alimentos como prazer legítimo e competente de saboreá-los, mediante experiência cultural que modela, apurando a percepção dos sentidos. Nesta perspectiva, talvez fosse mesmo plausível propor que da história e da sociologia da alimentação fossem banidos ou ocultados os pobres e, por extensão, o popular, de vez que neste universo não haveria sentido em problematizar o inexistente - hábitos alimentares referenciados por uma cultura.

No entanto, lido a contrapelo o sentido destas considerações, é possível partir desta excrescência política (quando "representantes do povo" entram em choque com os interesses deste) para lançar a seguinte indagação: em que consistiria uma cultura popular manifesta na alimentação? A fim de conduzir esta questão, talvez valha a pena evocar brevemente a reflexão de Roger Chartier em "CULTURA POPULAR": revisitando um conceito historiográfico (1995). Mesmo correndo o risco de simplificações, Chartier lembra que subjacente às dificuldades geradas pela categoria "cultura popular" própria ao pensamento erudito, concebida para ordenar e classificar um conjunto de práticas sociais heterogêneas e heterônomas, haveria dois grandes modelos de descrição e de interpretação:

\footnotetext{
O primeiro modelo explicativo abriga o intuito de abolir toda forma de etnocentrismo cultural, pois concebe a cultura popular como um sistema simbólico coerente e autônomo, que funciona segundo uma lógica absolutamente alheia e irredutível à da cultura letrada. $O$ segundo, preocupado em lembrar a existência das relações de dominação que organizam o mundo social, percebe a cultura popular em suas dependências e carências em relação à cultura dos dominantes. Temos, então, de um lado, uma cultura popular que constitui um mundo à parte, encerrado em si mesmo, independente, e, de outro, uma cultura popular inteiramente definida pela sua distância da legitimidade cultural da qual ela é privada (p.179).
}

Neste texto, Chartier adere à reflexão e à prudência de Jean-Claude Passeron quanto aos equívocos lógicos e metodológicos aos quais pode levar a oposição frontal e o emprego isolado destas duas definições de cultura popular. 
De fato, uma reflexão sociológica sobre a chamada cozinha regional, de base tradicional popular, pode abrigar um campo empírico bastante fértil para promover uma aproximação destas duas perspectivas interpretativas: aquela que enfatiza a autonomia simbólica da cultura popular e outra que insiste na sua dependência da cultura dominante.

Quanto ao termo "tradicional", este é empregado considerando que "tradição" alimentar é algo "inventado" (MONTANARI, 2008), momentaneamente estável, sendo passível de modificações. Fortemente vinculada à memória, a ideia de tradição alimentar abandona definitivamente qualquer ambição de correspondência exata a acontecimentos passados quando seu caráter seletivo é colocado em primeiro plano. Via de regra de forma não premeditada, a narração memorialística reconstrói trajetórias de vida de forma coerente e evolutiva, fazendo emergir do passado aqueles acontecimentos, sentimentos, sensações que afirmam a perspectiva presente.

Assim, resta considerar que, sobretudo em tempos de processos globalizantes, taiscozinhasregionais, de base popular e tradicional, não podem ser definidas como uma coisa ou outra, mas antes devem ser consideradas como uma coisa e outra, cuja dinâmica temporal e espacial implica em transformações, adaptações e diversificação.

\subsection{A emergência da cozinha tradicional popular e o campo gastronômico}

O fenômeno da desterritorialização de produtos, provocado pela intensificação dos fluxos de mercadorias estruturados por mercados globalizados, segundo Poulain (2013), fez com que os fast-food levassem inicialmente as cozinhas locais ao risco de desaparecimento. Minadas em seu valor e autonomia por uma tendência de pensamento que vinculava tradição e atraso, as expressões populares no campo alimentar recuaram até meados do século XX.

No entanto, os processos de globalização, realizados concretamente de forma heterogênea e desigual, acabaram por instigar a reação de culturas locais, com estas fundindo-se em diferentes medidas. Neste sentido, as cozinhas locais, que passam a ser concebidas como autênticas, tornamse o alvo de apropriações cujas referências estetizantes lhes conferem um padrão competitivo em termos de reconhecimento, projetando-as para fora de seu próprio território. O exemplo mais emblemático desta configuração é o caso francês. A chamada "cozinha de terroir" converte, nas mãos de chefs renomados, o saber ancestral de pratos ou o emprego de insumos tradicionais em refeições requintadas e produtos autorais.

Sob os auspícios deste processo de apropriação, as cozinhas regionais, de base tradicional e popular, foram postas em evidência, inclusive como forma de alicerçar os fluxos turísticos de pessoas. A afirmação profissional da figura do chef de cozinha; bem como o desenvolvimento de disciplinas acadêmicas que tematizam a alimentação sob diferentes perspectivas e o crescimento do chamado turismo de experiência, com ênfase na gastronomia; exigiam uma formulação discursiva que tomasse por objeto as dinâmicas que marcam o campo na contemporaneidade, seja no que tange à cultura alimentar promovida pela alta gastronomia, seja aquela que concerne à cozinha cultivada pelos segmentos populares.

Em Sociologie de l'alimentation, Faustine Régnier (2009) assinala que, de fato, vivemos um período no qual a alimentação tornou-se o objeto complexo de um número crescente de questionamentos e de publicações, constituindo-se como o alvo disputado por várias disciplinas acadêmicas, mas também pelo campo da saúde e das mídias. Isto porque as práticas alimentares tocam domínios tão variados quanto aqueles da cultura (na forma da gastronomia e do patrimônio 
culinário), da saúde (a questão da segurança alimentar e da prevenção nutricional), da economia (no que concerne ao orçamento, aos mercados alimentares, à produção) e, como vimos, da política. A autora lembra, no entanto, que toda esta diversidade não mascara o fato de que a alimentação acha-se ancorada em um fato central: a persistência de diferenças sociais em termos de consumo alimentar.

$\mathrm{Na}$ agenda de uma sociologia da alimentação que define seus objetos e métodos próprios, cabe então elencar a interpretação do espaço social alimentar a partir das questões impostas pela produção, circulação, preparação e consumo da comida que se encontram ao abrigo de determinadas culturas alimentares e das dinâmicas do gosto.

A noção de "espaço social alimentar", tal como apresentada por Poulain (2013), é utilizada como ferramenta metodológica. Um recurso apropriado para ir além das questões simbólicas, isto é, onde o conceito de cultura alimentar não consegue chegar. Assim, permite circunscrever as diversas dimensões que influenciam na alimentação humana: biológica, psicológica, geográfica, econômica, política e, sobretudo, sociocultural - pois, é um ponto de vista sociológico. Oferecendo, portanto, um panorama relacional dos fatores internos e externos que interagem na elaboração dos gostos populares.

Nesse sentido, no estado do Ceará, por um lado, percebe-se que o espaço social da cozinha tradicional popular tem guardado certa autonomia em um percurso histórico forjado por grandes disparidades econômicas e sociais entre os segmentos de população; e por influências naturais diversificadas (considerando os produtos de ao menos três microclimas: do sertão, das serras e do mar).Acrescente-se a isto a influência da presença indígena e de grupos migratórios, a exemplo dos sírio-libaneses e dos asiáticos. Juntos, tais fatores conferiram um perfil particular à cozinha popular cearense. Por outro, ela se acha também condicionada pela presença de insumos e de modelos alimentares massivos que continuam a marcar a atualidade dos processos de globalização.

Um caso particular desse movimento de englobar culinárias de base tradicional às lógicas do mercado alimentício internacional, tendo como foco o consumo turístico, é aquele representado pelo Centro das Tapioqueiras e do Artesanato de Messejana (CETARME). Este local, referência da "gastronomia regional cearense" desde o ano 2002, exemplifica como saberes e práticas tradicionais da elaboração da tapioca, ligados a uma classe social popular, foram moldados, por vontade política, aos "gostos" dos clientes estrangeiros. Apesar disso, mesmo que de maneira residual, esses manejos e conhecimentos ainda são utilizados pelos tapioqueiros remanescentes do momento de conversão da tapioca cearense em produto "tipo exportação".

Esse cenário parece descortinar uma passagem sintomática da estruturação do campo alimentar local: a cozinha regional, de base tradicional e popular, não só extrapola o universo doméstico, mas ganha a forma de restaurantes temáticos que se integram aos fluxos turísticos. Tal passagem encontra-se estruturada, inclusive pelo investimento do poder público municipal e estatal. O que desponta como diferencial nos últimos anos é uma nova simbologia, a qual vem revestir tais restaurantes de um viés cultural ou patrimonial, extrapolando a definição do popular restrita unicamente à dimensão financeira.

Neste sentido, encontra-se em jogo uma fusão semântica inesperada que faz recuar a designação de "cozinha regional" para projetar aquela da "gastronomia regional popular". Neste cenário, quais instituições e agentes têm impulsionado as dinâmicas do gosto popular que se desenham? 


\section{A EXPERIÊNCIA DO OBSERVATÓRIO CEARENSE DA CULTURA ALIMENTAR (OCCA)}

Em 2017, mobilizadas pelas diferenças sociais hierarquizantes em termos de consumo alimentar e pelo papel das culturas alimentares nas transformações ou permanências de experiências gustativas que marcam a cultura alimentar na contemporaneidade, duas instituições públicas e uma profissional ${ }^{6}$, uniram-se para fundar o Observatório Cearense da Cultura Alimentar (OCCA), em Fortaleza.

Ao longo do primeiro ano de existência pública, o Observatório tem incentivado pesquisas que apreendam qual variedade de gostos acham-se calcados na cultura alimentar de base regional popular gerada no Nordeste, e mais especificamente no Ceará. Foi com esse propósito que o Observatório organizou, ainda em 2017, uma edição do Percursos Urbanos ${ }^{7}$, com a temática: Aromas do tempo, sabores e memórias, a fim de evidenciar a ideia da culinária regional, a partir de um circuito de estabelecimentos que representassem o gosto do popular.

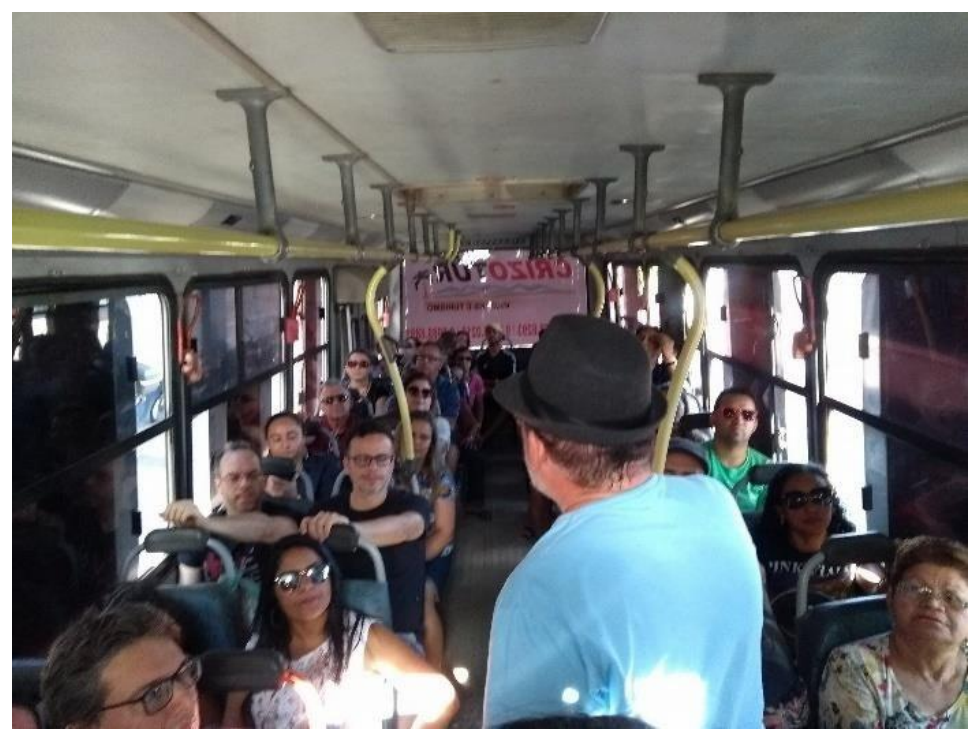

Figura 1. Edição Percursos Urbanos Fonte: autores (2017)

O OCCA propôs ao CCBN, à ONG Mediação de Saberes e ao público a realização de uma trilha gastronômica por três bares/restaurantes tradicionais na cidade de Fortaleza: o Bar "O Camocim", localizado no bairro Centro; o Bar e Restaurante "O Fabiano" (1950), instalado no bairro Jacarecanga; e o "Albertu's Restaurante", sediado no bairro Barra do Ceará. No material postado após a realização da atividade pode-se ler:

No interior do ônibus cedido pelo CCBN, os mediadores conduziram a programação, fazendo com que as visitas fossem regadas à história de cada bairro, dos fundadores dos três estabelecimentos, de sua influência e reconhecimento local, de informações sobre a opção por uma culinária tradicionalpopular, sobre sua trajetória de vida e de permanência no local. A cada parada do ônibus, o público foi presenteado com uma degustação dos

\footnotetext{
${ }^{6}$ A Universidade Estadual do Ceará (UECE), o Instituto Federal de Educação, Ciência e Tecnologia (IFCe) e a Associação de Chefs de Cozinha do Ceará (ACC).

${ }^{7}$ O Percursos Urbanos é uma programação cultural realizada periodicamente em Fortaleza e que consiste sempre em um trajeto temático pela cidade. Esta programação é mantida pela colaboração entre o Centro Cultural do Banco do Nordeste (CCBN) e a Organização Não-Governamental Mediação de Saberes.
} 
principais petiscos e pratos que caracterizam os locais visitados: o torresmo (no Camocim), a panelada (no bar O Fabiano) e o caldo de peixe (no Albertu's Restaurante).

O papel mediador de inversão simbólica que o Observatório assume neste caso condiz com um dos três eixos que o estruturam: a pesquisa, a formação e a intervenção. Neste caso, em face das histórias dos lugares visitados, dos ingredientes e dos costumes que persistem, das pessoas de sociabilidade simples que cultivam em seu cotidiano a memória dos sabores de uma cultura alimentar que, apesar da fluidez das modas inventadas e da disposição consumista, continua existindo.

\section{GASTRONOMIA REGIONAL, TRADICIONAL E POPULAR: SEUS GOSTOS, SEUS ROSTOS, SUAS VOZES}

A análise sociológica que se lança à compreensão das relações de tensão sistêmica que hierarquizam o campo da gastronomia ${ }^{8}$, polarizando-o entre alta e baixa gastronomia, tem sido pouco esclarecedora das condições sociais de possibilidade de existência e de perpetuação da chamada "gastronomia regional de base popular". Neste contexto, se o debate acerca dos efeitos das dinâmicas de globalização parece ter se unificado em função da construção de um novo consenso em torno da tendência inaugural desse movimento global, voltada à unificação dos gostos, ainda elevam-se questionamentos acerca dos sentidos da emergência do local, na forma das cozinhas regionais.

A conversão dos termos "cozinha" / "culinária" em "gastronomia" revela muito da complexidade dos processos sociais que se acham em curso. A tendência à gourmetização parece então colonizar as expressões da cultura alimentar de base regional, tradicional e popular, reconhecendo seu valor para em seguida promover uma alteração de rota cujo resultado final tem sido recorrente - tradições reinventadas em nome do requinte e da sofisticação, da integração em um circuito mais amplo de projeção nacional ou internacional.

O popular é alçado então, via de regra, a patamares superiores como se fosse o produto de uma falta. Inversamente, se analisados criticamente, os processos de gourmetização da comida regional parecem apontar novas formas de homogeneização, mais sutis, do popular. Como lugar da pluralidade que escapa e se reinventa frente a mecanismos sociais integradores, o popular afirmase assim a partir de uma cultura alimentar que, longe de ser substantiva e rígida, define-se na perspectiva sociológica de forma situada e relacional.

Se a noção de cultura alimentar alicerça as expressões do gosto do popular, conferindo-lhe valor identitário, é preciso considerar que o alargamento do campo gastronômico, na forma de uma gastronomia regional de base tradicional e popular, corporifica-se em sujeitos e grupos cujas práticas (inclusive discursivas) subsidiam a compreensão sociológica. Convertem-se nesta perspectiva, em sujeitos-objeto situados, cuja existência objetiva emerge de uma trama de elementos condicionantes que se relacionam e se reforçam. Neste artigo, serão considerados os seguintes elementos que configuram a expressão do gosto do popular a partir da perspectiva dos próprios sujeitos: o local, o ambiente, os utensílios e técnicas empregadas, o prato elaborado e o agente social, sujeito em sua condição física.

\footnotetext{
${ }^{8}$ Ver o artigo “Da gastronomia francesa à gastronomia global: hibridismos e identidades inventadas" (BUENO, 2016). 


\subsection{O local: arquitetura e representatividade histórica}

O bairro Jacarecanga, situado a oeste do bairro Centro de Fortaleza, é um dos mais antigos da capital cearense. Na década de 20, o bairro passou a integrar a histórica mudança da burguesia cearense que assim buscava evitar a convivência com os retirantes. Este segmento de população evadia-se para a capital, a fim de evitar os efeitos das estiagens periódicas que castigavam o sertão. Os casarões e sobrados que assinalam a paisagem do bairro testemunham as influências europeias sobre uma arquitetura acessível à faixa de população economicamente influente. $O$ local que hoje abriga o Bar/Restaurante o Fabiano é assim uma das edificações remanescentes que ratificam a memória do bairro.

$\mathrm{Na}$ década de 40, a Jacarecanga assistiu nova migração da elite cearense, acompanhando a mudança de eixo econômico da cidade, com a transferência do porto para o Mucuripe. A partir de então, o bairro entra em decadência, ao passo que outros despontam em termos de atração das camadas médias e ricas da população - trata-se da Aldeota, Praia de Iracema e Meireles. 0 proprietário do restaurante lembra que:

O estabelecimento existe desde 1958, quando o meu pai começou a trabalhar no local. Aqui era uma leiteria: Leiteria Jacarecanga. No tempo do meu pai, as coisas eram bem diferentes. $\mathrm{Na}$ década de 60, quando apareceu o leite pasteurizado, mudou o ritmo do comércio, porque não tinha mais mercado pra coalhada e aquelas coisas que se vendiam antes. 0 restaurante veio depois dessa transformação, em 1966. De lá pra cá, a gente vem trabalhando com comida regional e popular.

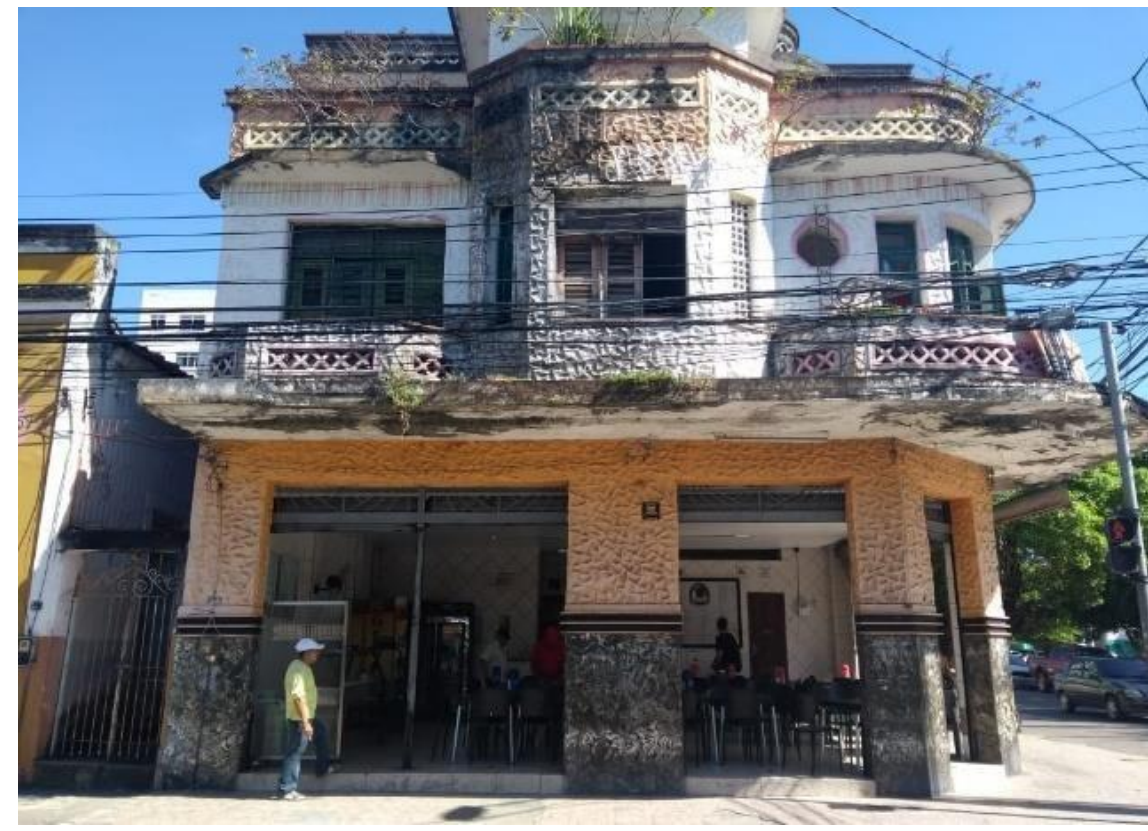

Figura 2. Bar/Restaurante O Fabiano

Fonte: autores (2017)

A longevidade do negócio familiar que envolve, neste caso, "cozinha caseira", nutre-se da relação com o entorno, materializada na própria edificação que abriga de forma articulada o restaurante e a casa, mas também a capacidade de adaptação do negócio às mudanças econômica, de clientela e de condições de produção do estabelecimento (extensão do sítio de propriedade do Sr. Fabiano e de sua esposa). 


\subsection{Um ambiente: as imagens, os cheiros e as relações entre as pessoas}
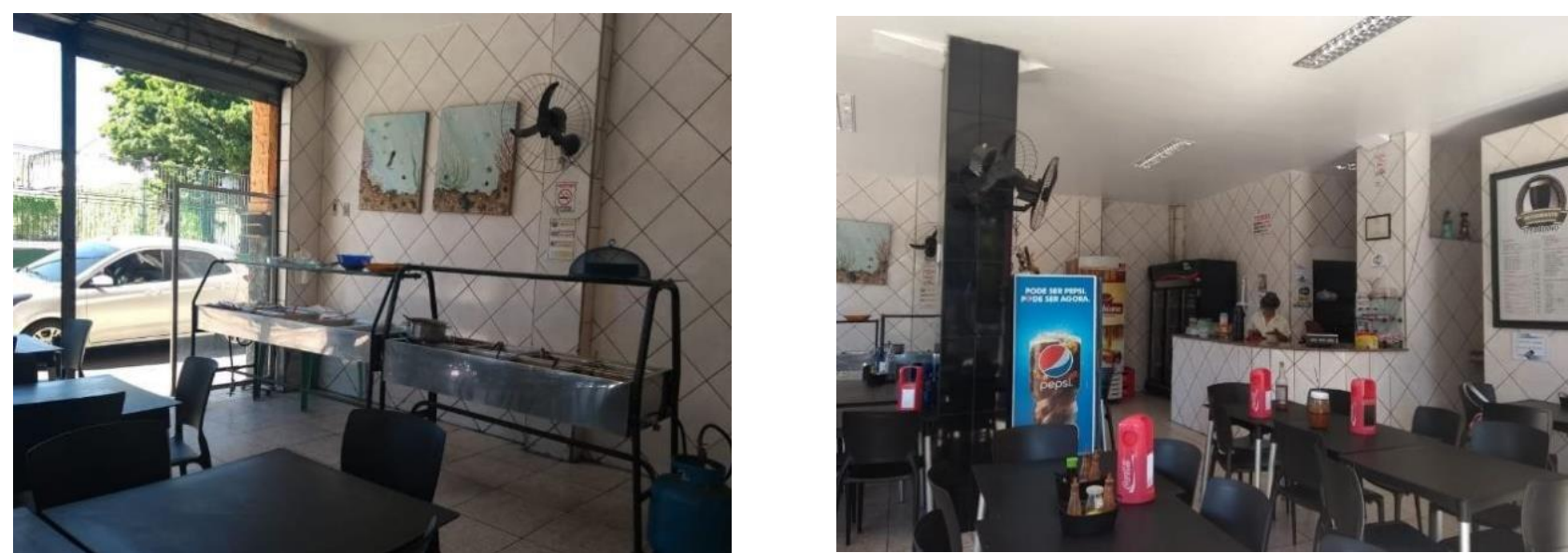

Figuras 3 e 4. Bar/Restaurante O Fabiano

Fonte: autores (2017)

Ambiente "simples", sem sofisticação decorativa, prático, pois organizado em função do selfservice que pauta o cotidiano do lugar, mas também do balcão que divide o espaço público do salão, daquele território privado representado pela cozinha. Mesas e cadeiras, as quais tanto podem abrigar individualmente clientes solitários, quanto juntarse em função de famílias inteiras que vêm ao estabelecimento nos fins de semana. Durante o dia, lá fora, o calor e a luminosidade induzem a clientela a entrar; do interior do restaurante, o aroma da comida, ultrapassa a cozinha, atravessa o salão e ganha a rua, atraindo aqueles(as) que passam, convidando-os(as) a sentar-se, usufruir da brisa produzida pelos ventiladores, da água de coco fresquinha, da cerveja geladíssima e dos pratos cujo principal ingrediente, segundo o proprietário, é a qualidade.

As relações entre as pessoas não se restringem ao perímetro circunscrito por cada mesa, mas estende-se ao reconhecimento dos clientes mais frequentes, à sociabilidade alargada àqueles que servem ao público ou se colocam atrás do balcão.

Nesse contexto, o popular ganha em concretude. Ele se constitui em um ambiente no qual os sentidos acolhem as imagens e os odores da comida, instituindo relações sociais diretas e práticas de comensalidade, conformando um público que integra sua definição.

\footnotetext{
Todo dia são feitas oito opções de carne, para o almoço que é self-service. Eu diria que a nossa comida é muito popular. Porque a gente atinge vários bairros da cidade, que vem de longe só pra comer da nossa panelada aqui. Do rico, dos profissionais liberais ao pessoal que trabalha por aqui. Mas dos bairros próximos, tem muita gente que frequenta aqui. $E$ sábado é o dia mais diferente, porque vem muitas senhoras, muitas famílias... porque durante a semana é mais o pessoal do dia-a-dia, mas de sexta pra sábado vem o pessoal de mais longe, de fora do bairro.
}

O ambiente do restaurante, porém, não se encerra no âmbito da experiência sensível. Ele abrange, de forma a ampliar-se, o ambiente virtual. Numa página no facebook mantida por uma das filhas do proprietário, sobressaem aspectos nutritivos do cardápio apresentado. Sua análise, no entanto, exigiriam a mobilização de outros recursos teórico-metodológicos, adequados à lógica própria das interações mediadas pelas redes sociais. 


\subsection{Apresentação da comida: utensílios e técnicas do popular}

Além da exterioridade representada pela edificação e da interioridade do ambiente do bar / Restaurante O Fabiano, o gosto do popular pode ainda ser sociologicamente problematizado a partir dos utensílios utilizados para a apresentação dos pratos. Como elemento mediador importante para intensificar a experiência de regionalidade que se inicia pelo consumo e pelo olhar, os clientes do estabelecimento O Fabiano deparam-se com a integração entre continente (a panela e o prato de barro cru) antes de descobrirem visualmente o conteúdo (a panelada).

Neste sentido, os instrumentos do consumo alimentar não se restringem apenas aos materiais mediadores acima elencados. Antes, podem erigir-se em elementos discursivos, a exemplo do cardápio ou a logomarca do restaurante nele aplicado. Sobre este ponto, o proprietário afirma:
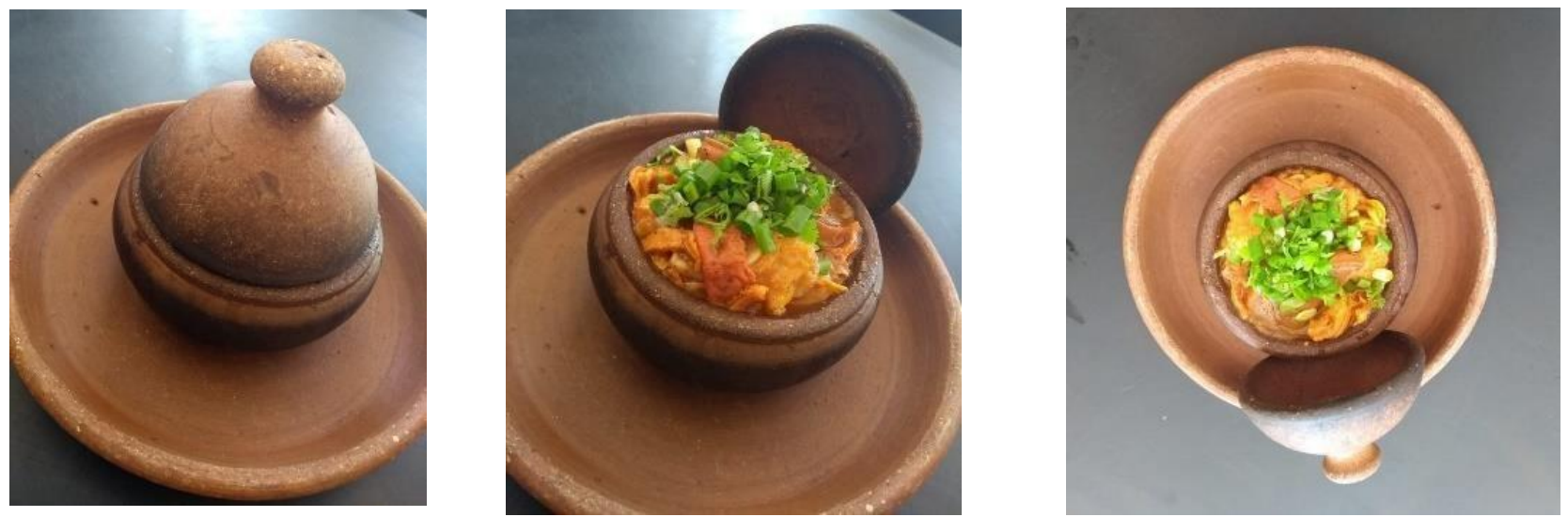

Figuras 05, 06 e 07. Bar/Restaurante O Fabiano

Fonte: autores (2017)

(Minha mulher) ${ }^{9}$ faz uma variedade danada de comida, não tem um cardápio fixo e varia muito. Tenho uma criação de carneiros e de vez em quando abate um, aí a gente faz uma buchada, mas não é toda semana não. Aqui tem sempre é assado de panela, cozido, caldo de mocotó e caldo de carne servidos diariamente, fora o self-service. Quando abrimos de manhã já é com tudo pronto, com caldo de carne e caldo de mocotó. Então, tem umas coisas fixas e aquelas que ficam mudando. Mas, a panelada é a única regional mesmo.

Neste caso, a cultura comunicacional letrada que fundamenta o emprego do cardápio revela-se como elemento representativo que estabelece elos frágeis com a realidade, cuja dinâmica frequentemente o ultrapassa. O cardápio, elemento tão bem integrado ao ecossistema de bares e restaurantes que servem às classes médias, parece assumir neste contexto uma função quase decorativa, supérflua, cotidianamente suplantada pela performance comunicativa daqueles que servem aos clientes.

\footnotetext{
${ }^{9}$ Maria Cleide da Silveira Medeiros.
} 


\subsection{Pratos tradicionais: o sabor e as preferências do popular}

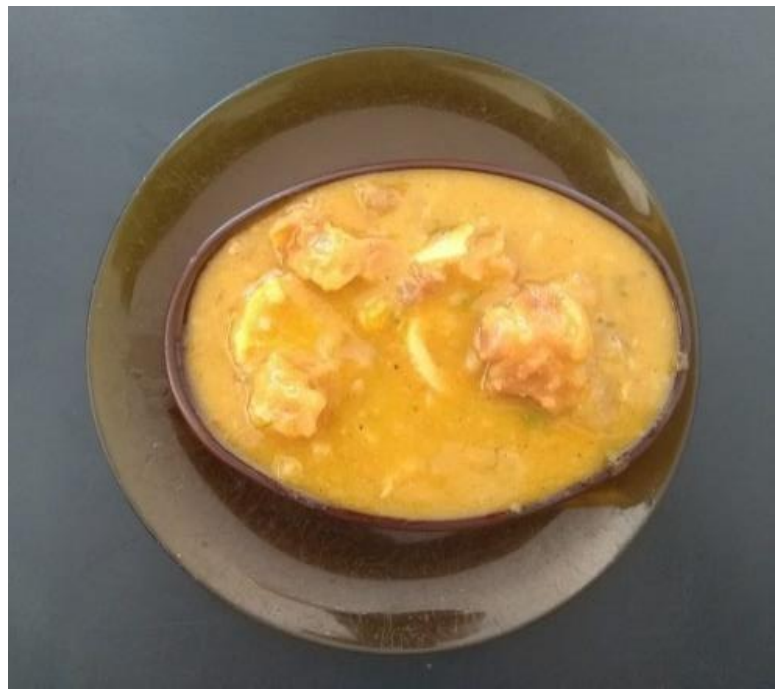

Figura 8. Caldo de Mocotó

Fonte: autores (2017)

Mesmo o conhecimento acumulado na preparação do prato considerado como tradição do restaurante - a panelada - parece ocupar um lugar incerto quando Fabiano caracteriza as preferências dos clientes. Apesar de ter se convertido em objeto de inovação comercial, a panelada - vendida por quilo e a vácuo para clientes que se municiam de recursos alimentícios adequados a momentos de viagens - cede lugar ao caldo de mocotó, considerado pelo proprietário como legítimo.

O caldo de mocotó é mais elogiado do que a panelada. Apesar de a gente trabalhar com isso há muito tempo, já ser tradicional, o caldo de mocotó legítimo quem faz somos nós. Apesar das propagandas de outros, o nosso é feito exclusivamente do mocotó. Se você chegar no Mercado São Sebastião, vários restaurantes dizem que servem caldo de mocotó, mas botam todo tipo de osso. Mas no meu nem a canela do mocotó nós botamos, só a pata com o regeto, feito aqui que nós vendemos no quilo. O legítimo, só eu faço aqui, porque o dos outros não chega nem perto do meu. Sendo o prato mais elogiado, além da panelada, é claro.

Neste ponto da análise, é preciso colocar em pauta a relação conflituosa estabelecida entre o popular segundo diferentes matrizes "tradicionais" da cultura alimentar cearense - aquela que veio do interior do estado, transportada pelas levas migratórias, que tinham por base os produtos advindos do gado e das carnes de criação (ovinos e caprinos); e aquela vinda do litoral, amplamente elaborada e difundida por uma indústria publicitária e comunicacional que configura um turismo que tem por base o sol e o mar.

Nesta disputa, historicamente comidas como a panelada, a buchada, o sarrabulho e o chouriço, foram relegadas ao segundo plano por desagradarem, pelo odor e pela aparência, a sensibilidade das levas turísticas, sobretudo aquelas de origem europeia. 


\title{
3.5 O sujeito popular: trajetória de vida, voz e presença
}

O senhor Fabiano da Silveira Medeiros, aos 73 anos, abre diariamente seu estabelecimento, de segunda à sábado, de $7 \mathrm{~h}$ da manhã às $21 \mathrm{~h}$. As portas são fechadas normalmente na hora do Jornal Nacional, exceto nos dias em que ocorre jogo de futebol. Tendo-se tornado proprietário do restaurante que leva hoje seu nome, na década de 60, trabalha desde os 13 anos de idade. Em sua trajetória de vida, ingressou no mundo do trabalho fazendo "de um tudo" na metalúrgica do meu vizinho. Ele conta como assumiu o restaurante: em 1964 ingressei no exército, mas, dois anos depois, saí fui trabalhar com meu pai. Eu era o filho mais novo, e meu pai disse que eu iria trabalhar com ele no restaurante e até hoje é assim.

Fabiano deu continuidade a um modelo de negócio que tem como base os laços familiares, gerenciando aquele que se tornou um dos restaurantes tradicionais no bairro Jacarecanga, mesmo que a princípio não houvesse uma habilidade clara para o trabalho com a área de alimentos.

\begin{abstract}
Quando comecei a trabalhar com meu pai eu não entendia de comida. Mas a situação vai empurrando a gente pra isso. Por exemplo, quando nós começamos a fazer panelada, era a pedido dos clientes e era só às sextas-feiras. Depois era quarta e sexta, e hoje a panelada não pode faltar de jeito nenhum. Mas não sou eu quem cozinha, nem pego em panelada.
\end{abstract}

Apesar de elencar as dificuldades de trabalho com comida regional e popular, ele faz um balanço positivo de seu trabalho afirmando a qualidade conquistada o levou ultrapassar a concorrência, possibilitando um rendimento que cobre as despesas de manutenção do negócio e das oito pessoas que se empenham em fazê-lo funcionar.

No ambiente do restaurante, o registro fotográfico em que o senhor Fabiano faz pose com o prato de panelada parece revelar que a crença que o moveu durante anos de trabalho permanece intacta. Ao concluir a entrevista afirmando que ainda tem muito a fazer no restaurante, ele abandona sua condição de indivíduo isolado para incarnara inversão simbólica provocada pela valorização do popular a partir de sua diferença. Neste caso, as condições sociais de possibilidade de tal inversão não emergem de uma externalidade, a exemplo das dinâmicas de gourmetização. Antes, tiveram seu lastro em mudanças de uma trajetória social pautadas por lógicas de sociabilidade popular e vivenciadas por este sujeito como simples "adaptações".

Nesse contexto, as emoções e a experiência dos sentidos não ocupam um lugar periférico. Por isso, a postura física e a expressão orgulhosa do senhor Fabiano testemunham o sentimento de persistência de uma cultura alimentar que, em um recente processo de reconhecimento, afirma-se como gastronomia regional, de matriz tradicional e popular.

\section{REFERÊNCIAS}

BAXANDALL, Michael. O olhar renascente: pintura e experiência social na Itália da Renascença. Rio de Janeiro: Paz e Terra, 1991.

BOURDIEU, Pierre. A metamorfose dos gostos. Questões de sociologia. Rio de Janeiro: Marco Zero, 1983.

A Distinção: crítica social do julgamento. São Paulo: Edusp; Porto Alegre: Zouk, 2007.

BRAGA, Vivian. Cultura alimentar: contribuição da antropologia da alimentação. Saúde em Revista, Piracicaba, v. 6, n. 13, jul. 2004. p.37-44. 
BUENO, Maria Lúcia. Da gastronomia francesa à gastronomia global: hibridismos e identidades inventadas. Caderno CrH, Salvador, v. 29, n. 78, p. 443-462, Set./Dez. 2016.

DAMATTA, Roberto. O que faz o Brasil, Brasil? Rio de Janeiro: Rocco, 2001.

GOJARD, Séverine; LHUISSIER, Anne; RÉGNIER, Faustine. Sociologie de l'alimentation. Paris: La Découverte, 2006.

GEERTZ, Clifford. A interpretação das culturas. Rio de Janeiro: LTC, 1989.

LARAIA, Roque de Barros. Cultura: um conceito antropológico. Rio de Janeiro: Jorge Zahar Editor, 1997.

MONTANARI, Massimo. Comida como cultura. São Paulo: Senac, 2008.

MORIN, Edgar. O Método 5: a humanidade da humanidade. Porto Alegre: Editora Sulina, 2007.

POULAIN, Jean Pierre. Sociologias da Alimentação: os comedores e o espaço social alimentar. Florianópolis, UFSC: 2013.

SANTOS, José Luiz dos. O que é Cultura. São Paulo: Brasiliense, 1994. 